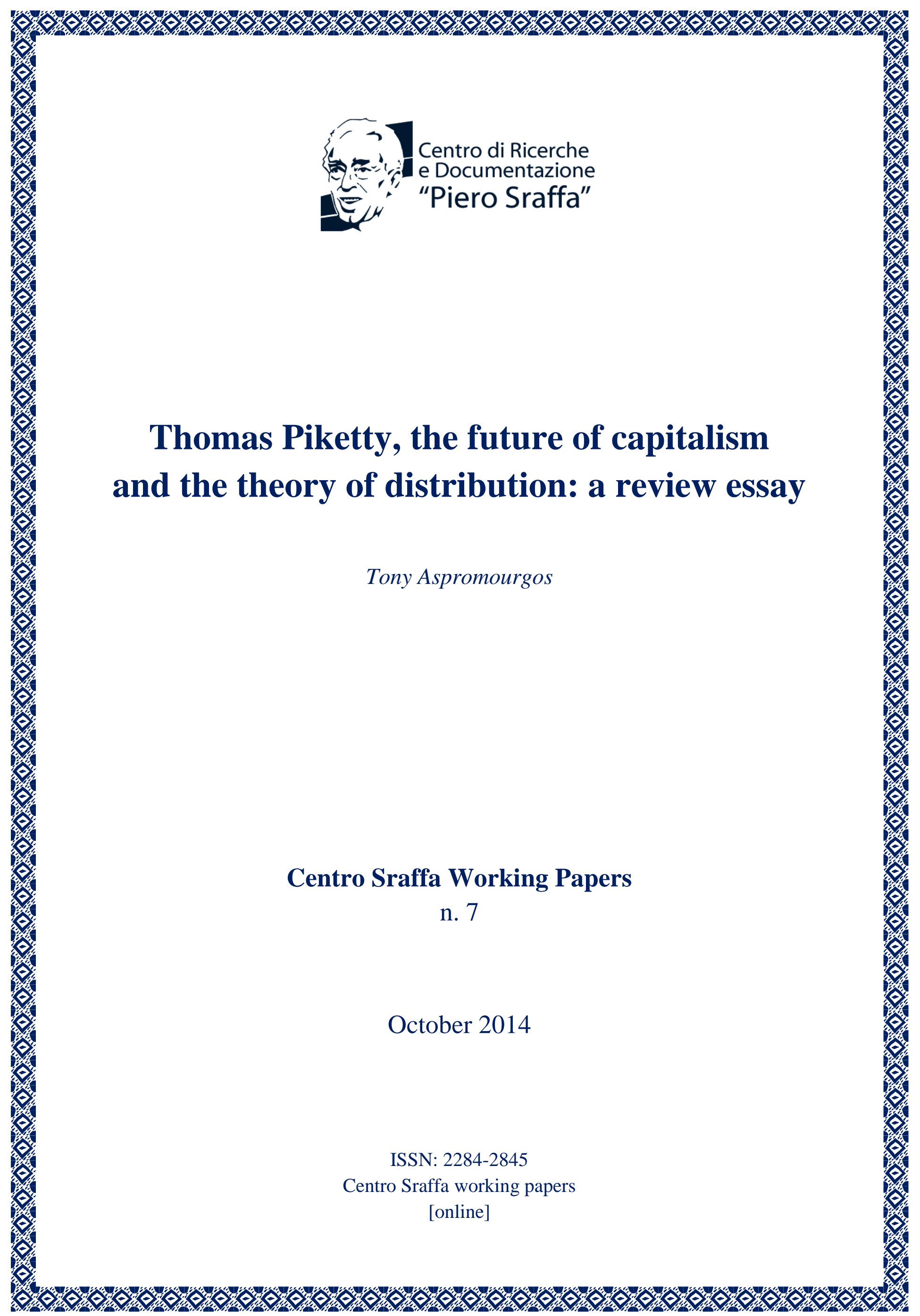




\title{
Thomas Piketty, the Future of Capitalism and the theory of Distribution: a Review Essay
}

\author{
Tony Aspromourgos* \\ University of Sydney
}

\begin{abstract}
This essay reviews Thomas Piketty's Capital in the Twenty-First Century (2014). The focus is upon the conceptual framework and theoretical interpretation of the empirical findings assembled in the book, rather than those empirical findings themselves (which are, in any case, broadly incontestable). The core theoretical logic of the distributional dynamics is explained and subjected to scrutiny with respect to the theory of distribution in particular, but also the theory of growth.
\end{abstract}

Keywords: classical economics, functional distribution, Keynesian economics, Piero Sraffa

JEL codes: B51, D31, D33, E12

\section{INTRODUCTION}

If one were to suggest an appropriate epigraph for Thomas Piketty's new book, David Ricardo's famous statement in the Preface to his Principles of Political Economy and Taxation (1951 [1817], p. 5) might be a worthy candidate: '[t]o determine the laws which regulate ... distribution, is the principal problem in Political Economy'. ${ }^{1}$ One might also offer the title of book I of Adam Smith's Wealth of Nations (1976 [1776], p. 13): 'Of the Causes of Improvement in the productive Powers of Labour, and of the Order according to which its Produce is naturally distributed among the different Ranks of the People'. In short, Piketty's book revives the great macro-historical issues of classical economics; in particular, the long-run dynamics of economic growth, income distribution and the interrelations between the two. And the author makes clear his disenchantment with the priorities of contemporary, mainstream academic economics,

\footnotetext{
* The author is indebted to Heinz Kurz and Graham White for advice, without thereby implicating them in the final product.

${ }^{1}$ Thomas Piketty, Capital in the Twenty-First Century (Cambridge, MA: Belknap Press of Harvard University Press, 2014); translated by Arthur Goldhammer, from Le Capital au XXI Siècle (Éditions du Seuil, 2013); pp. ix + 685; ISBN 978-0-674-43000-6. As a matter of fact, the Introduction to the book does have an epigraph, drawn from the 1789 Declaration of the Rights of Man and the Citizen (1; cf. 630, n. 20).
} 
in terms of its substantive scope and concerns, as well as the methods and theoretical constructs that dominate it $(15-16,31-33 ; c f .267,296,437,514$ on economists, and 636, n. 20 on the Economist magazine). The penultimate section of the last chapter of the book offers a description of what good economics, embedded in wider social science, should look like (573-5).

The central theme is the dynamics of income and wealth distribution since the eighteenth century, with the evolving relation between the GDP growth rate and the average rate of return on non-human wealth or income-earning property understood as the crucial factor. Importantly, anything akin to mechanical determinacy of distributional outcomes is explicitly eschewed. There is intrinsic contingency as a consequence of contending forces in the distributional dynamics; and the role, both actual and legitimate, of politics and policy in shaping distributional outcomes is vigorously affirmed (20-27, 69-71,234, 237, 255, 576-7). A world of 'fully guaranteed property rights' and '“purer and more perfect" competition' cannot ensure desirable distributional outcomes (30); the tendency towards rising inequality 'has nothing to do with any market imperfection' $(27 ; c f .96,370,423-4,512)$. Due to limitations of data availability the empirical focus is on France, Germany, Great Britain, Japan and the United States (27-8), though by no means limited to those countries, and to some extent, the book has a global scope.

It is first and foremost a very large-scale empirical study, embodying the highest standards of which such scholarship, in application to wealth and income distribution, is capable (given the data limitations), and drawing upon results from research collaborations with many other scholars, over a long period (vii-viii, 17-19). But the book is also informed by theory, and to a certain extent, constitutes a challenge to conventional economic theory. Our focus in what follows is the conceptual framework and theoretical interpretation of the empirical findings assembled in the book, rather than those empirical findings themselves. The latter are, in any case, broadly incontestable.

\section{THE CORE DISTRIBUTIONAL DYNAMICS}

The core logic of Piketty's analysis is built around two fundamental equations. First, there is an identity linking ratios of the aggregate stock of 'capital' $(K)$, aggregate net income $(Y)$ and aggregate nonwage income $(R)$, at the level of national economies:

$$
\begin{aligned}
& K / Y=(R / Y) /(R / K) \\
& \beta=\alpha / r
\end{aligned}
$$

where $\beta, \alpha$ and $r$ are, respectively, the ratio of aggregate 'capital' to income, the share of nonwage income in that income, and the aggregate ratio of nonwage income to 'capital', 
the latter called 'the rate of return on capital' (52-5). It is to be emphasized that the 'capital' of Piketty's title is not actually capital in the strict economic sense:

capital is defined as the sum total of nonhuman assets that can be owned and exchanged on some market ... [It] includes all forms of real property (including residential real estate) as well as financial and professional capital (plants, infrastructure, machinery, patents, and so on). (46)

It includes also natural resources and is defined net of financial liabilities $(45-50,113)$. But it does not incorporate any durable consumption goods other than housing and 'valuables' as defined in the international standards for national accounts - 'items such as works of art, jewelry, and precious metals' - and Piketty's empirical evidence shows that the value of the latter assets, together, amount to only between thirty-five and sixty per cent of aggregate income in recent decades (179-80).

Piketty's fundamental empirical finding is that the behaviours of $\beta$ and $\alpha$ over the last two centuries are described by U-shaped curves, but with the former's U-shape more pronounced due to the intervention of the behaviour of $r(199-203,216)$. Since rising $\beta$ is interpreted as the normal tendency of capitalist dynamics, the decline and bottoming out of $\beta$ expresses a sort of interregnum, centred on the three decades after World War Two (but with roots stretching back to World War One). Where there are difficulties in the way of accurately measuring the nonwage income share directly, Piketty in those situations suggests determining $\alpha$ by recourse to an independently determined measure of $\beta$, combined with a 'plausible' $r$ (five per cent being his general, average figure for the latter), so that $\alpha$ becomes a mere artefact of $\beta$ and $r(53,204)$. As he observes elsewhere, equation (2) can be viewed 'as a definition of the share of capital in national income (or of the rate of return on capital, depending on which parameter is easiest to measure)' (169; emphasis added). His empirical results lead him to the conclusion that ' $[t]$ he pure rate of return to capital is roughly stable around 4-5 percent in the long run' (202) - this 'pure' rate being, not a riskless rate, but rather an aggregate average rate net of an estimate of informal capital management costs (205-08).

The second of the two fundamental equations links $\beta$ also with saving and growth rates, but unlike the first equation, is only supposed as valid 'in the long run':

$$
\beta=s / g
$$

where $s$ is characterized as saving net of depreciation as a proportion of national income (593, n. 2) and $g$ is the growth rate of national income. The rationalization is as follows. If the level of aggregate net private saving in a given time-period $\left(S_{\mathrm{t}}\right)$ is identified with the change in the capital stock over that period $\left(\Delta K_{\mathrm{t}}\right)$, then:

$$
\left.\Delta K_{\mathrm{t}} / \Delta Y_{\mathrm{t}}=\left(S_{\mathrm{t}} / Y_{\mathrm{t}}\right) /\left(\Delta Y_{\mathrm{t}} / Y_{\mathrm{t}}\right)\right]=s_{\mathrm{t}} / g_{\mathrm{t}}
$$


where $\Delta Y_{\mathrm{t}}$ is the change in $Y$ in period $\mathrm{t}$. If this is then equated with the capital-income ratio $\left(\beta_{\mathrm{t}}\right)$ :

$$
\begin{aligned}
& K_{\mathrm{t}} / Y_{\mathrm{t}}=\Delta K_{\mathrm{t}} / \Delta Y_{\mathrm{t}} \\
& \Delta Y_{\mathrm{t}} / Y_{\mathrm{t}}=\Delta K_{\mathrm{t}} / K_{\mathrm{t}}
\end{aligned}
$$

So equation (3) is strictly valid only on the supposition of a stationary $\beta$ - or a steadystate growth path in the sense of equation (6). Or it can be interpreted as an 'asymptotic law' determining the value to which $\beta$ converges in the limit, for given values of $s, g$, stable over time:

$$
K_{\mathrm{t}+1}=K_{\mathrm{t}}+S_{\mathrm{t}}
$$

Letting $Y_{\mathrm{t}+1}$ equal $\left(1+g_{\mathrm{t}}\right) Y_{\mathrm{t}}$ and dividing through by $Y_{\mathrm{t}+1}$ :

$$
\beta_{\mathrm{t}+1}=K_{\mathrm{t}+1} / Y_{\mathrm{t}+1}=\left(\beta_{\mathrm{t}}+s_{\mathrm{t}}\right) /\left(1+g_{\mathrm{t}}\right)=\beta_{\mathrm{t}}\left[1+\left(s_{\mathrm{t}} / \beta_{\mathrm{t}}\right)\right] /\left(1+g_{\mathrm{t}}\right)
$$

If $s_{\mathrm{t}} / \beta_{\mathrm{t}}$ (the growth rate of wealth) equals $g_{\mathrm{t}}, \beta$ is stationary ( $c f .232$ ); or, if $s$ and $g$ stabilize at constant values, $s_{\mathrm{t}} / \beta_{\mathrm{t}}>g_{\mathrm{t}}$ will cause $\beta$ to rise, and $s_{\mathrm{t}} / \beta_{\mathrm{t}}<g_{\mathrm{t}}$ will cause $\beta$ to fall, $\beta_{\mathrm{t}}$ thus converging upon $s / g$. The latter convergence dynamics are how Piketty characterizes the significance of equation (3) (166-9, and p. 28 of the online Technical Appendix, available at http://piketty.pse.ens.fr/capital21c).

Hence, when Piketty uses this equation to compute values of $\beta$ for different values of $s, g$ (e.g., 166-7), he is really comparing distinct steady-state paths that have constant, but different, capital-income ratios. Furthermore, the identity, $S$ equals $\Delta K$, only holds, either under the condition of stationary asset prices (notably, on an equilibrium growth path with stationary relative commodity prices and rates of return on all capital assets); or if, instead, it is limited to the value of wealth or capital assets at the historical prices at which they were acquired, rather than their subsequent marketable value, which may deviate from acquisition prices. (For an example of the significant role valuation effects might play, see the discussion of the German 'paradox' (144-6).) Piketty's empirical $\beta$ measures marketable wealth at current values (149); so to employ this $\beta$, together with measures of $g$, to infer an empirical saving ratio is strictly invalid. As a consequence of any divergence between marketable values and acquisition prices, Piketty's $s$, at best, will be an aggregate measure of saving plus capital gains, relative to income.

$\mathrm{He}$ is well aware of that, noting that if asset prices rise faster than commodity prices and incomes, then $\beta$ can rise 'without the addition of any new savings' - but suggests that asset prices and commodity prices will tend to change at similar rates over the long run (169), so that enduring changes in wealth are generally, but not entirely, explained by saving (175-6). He also notes the role that the value of unimproved natural resources may play in aggregate wealth, independent of saving (169; cf. 446, 459, 537-8; and 461-2 on 'windfalls'). There is as well the issue of business saving: 
stock prices tend to rise more quickly than consumption prices over the long run, but the reason for this is essentially that retained earnings allow firms to increase their size and capital (so that we are looking at a volume effect rather than a price effect). If retained earnings are included in private savings, however, the price effect largely disappears (176-7).

While inclined to the view that most of $\beta$ can be explained by $s / g$, in discussing the mystery of land values', he acknowledges that low growth rates make estimates of $\beta$ highly sensitive to variations in $s$ estimates (196-8). Recalling that Piketty's 'capital' includes housing, $s$ in fact includes also in the numerator consumption spending in that sense. He observes that residential real estate as a whole 'currently accounts for roughly half the capital stock in the developed countries', this being inclusive of the value of the land on which the housing is located $(48,51)$; and it displays dramatic increase as a share of his measure of total capital/wealth, in the course of the twentieth century (e.g., 116-20, 141). In figures for France, house rents constitute one-third of $\alpha$ in 2010 (2267).

It is worth noting in this context that housing of at least a minimal kind is part of the necessary consumption of the population, and of the workforce and its dependents in particular. I use 'necessary consumption' here in the sense of Smith's (1976 [1776], p. 870) classical notion of subsistence as governed by social norms, so as to include 'whatever ... custom ... renders it indecent for creditable people, even of the lowest order, to be without'. To that extent, a large part of the housing of the bulk of the population is not 'wealth' at all, in the sense that it is not a resource available for discretionary use; it is not 'surplus to requirements', as the saying goes. This is obviously far less true of the housing of the rich, spending upon which - even if, for accounting purposes, it is treated as 'investment' - is, in substantive terms, luxury consumption. Perhaps, then, one should contemplate the wealth statistics with only the housing of, say, the top 10 or 20 per cent of wealth-holders or income-earners included. While Piketty's 'capital' is not capital in the strict sense, his capital-as-marketablewealth is a valid measure of economic power as marketable command over resources. But the bulk of owner-occupied housing does not constitute an accumulated surplus over and above consumption, available for discretionary use. Even if imputed rents are accounted for (see note 2 below), including the housing of the bottom 90 or 80 per cent still understates the maldistribution of wealth and incomes to the extent that the rate of return used to calculate imputed rents is less than the average rate of return on the wealth of the top 10 or 20 per cent.

The notion of the three or so decades after World War Two as an aberration in the history of capitalism is a familiar one, particularly in relation to unemployment, a relatively salient phenomenon. Piketty shows that it is also aberrant for distributional reasons. The two phenomena are surely connected, subsequent mass or high unemployment making easier the shifting of distribution in favour of property income 
and the rich more widely. In Piketty's analysis, the distributional interregnum is explained by the two World Wars, war-fuelled inflation and global depression leading to destruction of wealth (including loss of foreign wealth due to decolonization) and lower saving rates - these factors reducing the influence of inherited wealth - combined with vigorously redistributive policies and reduced asset prices, and accompanied, particularly after the second of those wars, by growth rates in excess of average returns on wealth $(41-2,77,83-5,106-09,118,121-2,146-50,274-6,368-76,514)$. Destruction of previously accumulated wealth (or of its value), expropriation of wealth and high incomes via policy, and relatively high growth rates are the (non-typical) conditions that can arrest and reverse a normal tendency towards rising inequality under capitalism. Inequality within the wages-and-salaries income category has been relatively stable over the twentieth century (271-4) and there is no logical necessity for the personal distribution of labour income to be positively and highly correlated with the personal distribution of income from wealth (254-5). The 'profound' change evident in the latter decades of the twentieth century is the importance of high managerial 'labour' incomes in the total incomes of the top decile of the distribution, particularly in the Anglophone developed economies (276-8, 302-03). Piketty also notes that the rise of a propertied middle class was 'the principal structural transformation of the distribution of wealth in the developed countries in the twentieth century' (260-62; also 251-2, 346-7, 350).

For an intuition of these distributional dynamics, consider the growth of wealth over one time period, assuming no capital gains (including no revaluations of unimproved natural resource stocks), wealth destruction or wealth taxation. (We also leave aside inheritance, discussed in section 3.) Divide the population into 'the rich' and 'the poor', where the former are a minority of the population with relatively high wealth per capita or per household. Suppose $a$ is the rich's share in total, nonwage plus wage income $\left(Y_{\mathrm{t}}\right)$, the poor receiving the remainder; $b$ is the proportion of the beginning-of-period total stock of wealth $\left(K_{\mathrm{t}}\right)$ owned by the rich, the poor owning the rest; and the saving rates of the rich and the poor are $s_{\mathrm{R}}, s_{\mathrm{P}}$ respectively. The growth of the rich's wealth over the period is:

$$
s_{\mathrm{R}} a Y_{\mathrm{t}} / b K_{\mathrm{t}}=s_{\mathrm{R}}(a / b) / \beta_{\mathrm{t}}
$$

And the growth of the poor's wealth is:

$$
s_{\mathrm{P}}(1-a) Y_{\mathrm{t}} /(1-b) K_{\mathrm{t}}=s_{\mathrm{P}}[(1-a) /(1-b)] / \beta_{\mathrm{t}}
$$

The former will exceed the latter if:

$$
\begin{aligned}
& s_{\mathrm{R}}(a / b)>s_{\mathrm{P}}[(1-a) /(1-b)] \\
& s_{\mathrm{R}} / s_{\mathrm{P}}>[b /(1-b)][(1-a) / a]
\end{aligned}
$$


It is reasonable to assume $s_{\mathrm{R}}>s_{\mathrm{P}}$. Many $(a, b)$ combinations will then satisfy inequality (12); but in particular, so long as $a \geq b$, the right-hand side is less than or equal to unity. That is to say, given $s_{\mathrm{R}}>s_{\mathrm{P}}$, if the rich's share of aggregate income is at least as great as their share of wealth, the growth of their wealth necessarily exceeds that of the poor. But it may do so even if the rich's share of income is less than their share of wealth, depending upon how much $s_{\mathrm{R}}$ exceeds $s_{\mathrm{P}}$. (Of course, with the rich and poor experiencing different growth rates of their wealth, and those growth rates differing from the growth of incomes, neither $a$ nor $b$ will be invariant over time; nor need $s_{\mathrm{R}}, s_{\mathrm{P}}$ be.) In fact, given the definition of 'capital' that is entailed by Piketty's $\beta$, the rich's 'saving' rate is inclusive of their spending on (new) owner-occupied real estate. The wealth of the rich might also enjoy more scope for capital gains, although thereby also perhaps more prone to the ups and downs of asset price fluctuations $(303,446$; but $c f$. 450 , where it is concluded that volatility of returns does not rise with scale of wealth). The rich also have greater access to tax avoidance and evasion (281-4, 294-5, 451-2, 465-7).

With regard to the significance of $g / r$, by substituting equation (2) into equation (9), the growth of the rich's wealth may be expressed as:

$$
s_{\mathrm{R}}(a / b) / \beta_{\mathrm{t}}=s_{\mathrm{R}}(a / b) r_{\mathrm{t}} / \alpha_{\mathrm{t}}
$$

The condition for this to exceed the growth of aggregate income is then:

$$
\begin{aligned}
& s_{\mathrm{R}}(a / b) r_{\mathrm{t}} / \alpha_{\mathrm{t}}>g_{\mathrm{t}} \\
& s_{\mathrm{R}}>\alpha_{\mathrm{t}}(b / a)\left(g_{\mathrm{t}} / r_{\mathrm{t}}\right)
\end{aligned}
$$

In general, many $(a / b),\left(g_{t} / r_{\mathrm{t}}\right)$ combinations will satisfy this inequality; $a \geq b$ with $g_{\mathrm{t}}<r_{\mathrm{t}}$ is sufficient for the right-hand side to be less than unity. Is it possible for the poor's wealth to grow more rapidly than aggregate income as well, even if less rapidly than the rich's wealth? Assuming, for the moment, that all wealth-owners receive the same uniform rate of return, and substituting equation (2) into equation (10), for the growth of the poor's wealth to exceed the growth of aggregate income:

$$
s_{\mathrm{P}}>\alpha_{\mathrm{t}}[(1-b) /(1-a)]\left(g_{\mathrm{t}} / r_{\mathrm{t}}\right)
$$

If $a>b$, then $[(1-b) /(1-a)]$ is greater than unity; so that in order for the poor to increase their wealth relative to aggregate income they face a greater hurdle than the rich. For the poor's wealth to grow faster than the aggregate income of just the poor themselves, will depend also on how $a$ is changing over time.

The combination $s_{\mathrm{R}}>s_{\mathrm{P}}$ and $r>g$ - assisted by $a \geq b$, but it is not essential - captures the core logic of Piketty's results. In the words of Jesus, to whoever has, shall even more be given (Gospel of St Matthew, chapter 13, verse 12). By starting ahead of the rest of the population, the rich as a whole can relatively easily get even further ahead. 
The principal reason why $a \geq b$ can prevail in reality, for a class of wealthy, high income-earners, are that those already relatively wealthy have access to higher rates of return on income-earning wealth, so that their share of nonwage income will tend to exceed their share of wealth $(201,206,243,376,405-06,430-55)$; and while it is logically possible that the distribution of 'labour' income could, to some degree, counterbalance this, at least in the modern era high incomes at the top end of the labourincome distribution are reinforcing the income inequality resulting from wealth inequality $(263-5,276-81)$. In relation to the former, owner-occupied housing, which earns no income, will be a much larger proportion of the wealth of lower income groups, often, their only significant wealth $(260,454) .^{2}$ In fact, rising income inequality in the US since the 1970s is 'largely the result of an unprecedented increase in wage inequality', particularly due to high managerial incomes - and not compensated for by wage mobility over the life cycle (298-300). (Conditions analogous to inequalities (12) and (15) can hold for persons with low wealth, initially, but high labour incomes, and thereby also high saving rates - so that their wealth grows faster than that of the rest of the population and faster than aggregate income.) Across contemporary developed economies, the poorest 50 per cent own hardly any wealth at all $(257-9,438)$.

In any case, the growth of the rich's wealth can still exceed that of the poor, even if the rich's share of income is less than their share of wealth, depending upon how much $s_{\mathrm{R}}$ exceeds $s_{\mathrm{P}}$ (inequality 12); and it can still exceed aggregate income growth, depending upon also the values of $\alpha$ and $g / r$ (inequality 15). Recall as well that the 'saving' rate which is required to satisfy these inequalities includes spending on (new) owner-occupied housing. Finally, in the absence of wealth destruction and taxation, at least in the long run - and with the ups and downs of short-run asset price fluctuation washing out - the wealth of the rich is likely to enjoy more scope for capital gains (including in relation to the scarcity value of land in prime residential locations). Systematic movements in asset prices, particularly housing prices, in Europe, play a significant role in both the 1913-1950 'dizzying' decline of $\beta$ ('one-quarter to one-third of the drop') and its rise from the 1970s forward (148-50; over the same period, $\beta$ was much more stable in the US: 154-5). In Piketty's analysis, the dominant factors explaining the latter, rising trajectory is lower growth combined with a high saving ratio; but also playing a significant role, privatization of public assets from the 1970s to the 1990s (commonly at below market prices: 185-7), and more importantly, real estate and share price trends in the 1980s and 1990s, conceived of as a correction or 'rebound' in relation to the earlier trajectory of asset prices (172-3, 183-91, 293-6, 451). Rising

\footnotetext{
${ }^{2}$ It is not clear whether or to what extent imputed rents from owner-occupied housing are included in the measures of income employed in Piketty's data. Presumably they generally are; and to that extent, owneroccupied housing in the denominators of $r$ and $\alpha$ is accompanied by imputed income flows in the numerators, based on some presumed rate of return on housing (a real rate of 3-4 per cent is suggested at $454)$ - and similarly for $\beta$. The only slight explicit references to the issue are in the note accompanying Figure 6.7 - 'rental value of dwellings' - which suggests that imputed rents are included there at least (226); and in an endnote indicating that imputed rents ('fictive rents') are excluded from Figure 8.4 (604, n. 12).
} 
asset prices explain one-quarter to one-third of the 1970-2010 rise in $\beta$ in the rich countries (191). ${ }^{3}$ On the tentative supposition of global $s$ stabilizing at ten percent and a trend global $g$ of 1.5 per cent, Piketty suggests the possibility of $\beta$ converging upon 700 per cent in the course of the twenty-first century (195-6, 233; at 431 the possibility of 3.5 per cent global growth until 2030 is allowed).

\section{CAUSATION AND THEORY}

What precisely is the causal structure of the normal distributional dynamics displayed in Piketty's empirical results, as understood by him? Before answering that question, a further theoretical postulate to which he has recourse must be noted.

However classical the questions Piketty addresses, when he turns to explain the determination of $r$ he has recourse to the conventional, post-classical marginal productivity theory of distribution: diminishing marginal capital productivity is 'natural' and 'obvious' (212-16). (He is much less willing to have recourse to time preference: 358-61; cf. 399-400.) The logical critique of capital aggregates - applied either at the macro or micro level - as supposed independent explanatory variables in the theory of profit rates, first coherently stated by Piero Sraffa (1960, pp. 81-7; see also Kurz and Salvadori 1995, pp. 427-67), is nowhere acknowledged or addressed. That such a relatively well-read economist as Piketty can so unhesitatingly apply this bankrupt approach, is testament to how completely a valid body of critical theoretical analysis can be submerged and forgotten in social science (a phenomenon for the sociologists of knowledge to contemplate). This is so, notwithstanding that Piketty offers a brief interpretation of the 'Cambridge' capital debates, making them turn upon the issues of whether there is substitutability in production (and associated flexibility of capitaloutput ratios), and whether or not 'growth is always perfectly balanced [i.e., fullemployment growth]' (230-32). In fact, the participants on both sides of those debates were concerned with production systems in which substitution and capital-output variability occurred; and continuous full-employment growth was not entailed by recourse to orthodox, marginalist production functions, a point perfectly understood by the participants on both sides. Marginal productivity theory is also applied to relative wage rates, although with much more substantial qualifications - and with regard to the highest 'labour' or managerial incomes, to the point of almost nullifying at least its practical relevance $(304-21,330-35,416-18,509-12$; at 331, 'close to a pure ideological construct'). With regard to profits, Piketty later comments: 'there is something astonishing about the notion that capital yields ... income that the owner of

\footnotetext{
${ }^{3}$ Even if, in the very long run, asset-price changes don't much matter for the magnitude of $\beta$, the fact that asset-price movements might wash out over periods of eight or more decades is of no moment for actually existing human beings whose saving lifespan is four decades or so (putting aside intergenerational motivation) (cf. 286-7, 488-9).
} 
capital obtains without working. There is something in this notion that is an affront to common sense and that has in fact perturbed any number of civilizations' (423). ${ }^{4}$

Piketty's embrace of the production function approach actually raises a potential problem for him, in reconciling the theoretical implications of that approach with his empirical findings: the theory entails (at least under competitive conditions) that rising $\beta$ will cause declining $r$, with the direction of change in $\alpha$, in general, indeterminate (see equation (2)). His escape route - it is the only possible escape route and therefore the necessary route for him, so long as he adheres to marginal productivity theory - is to impose a restriction upon the elasticity of capital/labour substitution, so as to ensure the compatibility of $\beta$ and $\alpha$ both rising through time. With the elasticity of substitution of capital for labour supposed greater than unity, the production function approach generates this outcome (216-24). A CES production function is posited:

$$
Y=\left[x K^{(\sigma-1) / \sigma}+(1-x) L^{(\sigma-1) / \sigma}\right]^{\sigma /(\sigma-1)}
$$

where $Y, K$ and $L$ are the standard aggregate production function variables, $x$ is a positive parameter $(<1)$ and $\sigma$ is the elasticity of substitution. The marginal productivity of capital is then $x \beta^{-1 / \sigma}$ and the capital share is given by,

$$
\alpha=r \beta=x \beta^{(\sigma-1) / \sigma}
$$

Thereby, $\alpha$ is an increasing function of $\beta$ if $\sigma>$ unity (online Technical Appendix, $\mathrm{p}$. 38). Piketty adds that the upward trend of both $\alpha$ and $\beta$ since 1970 is consistent 'also with an increase in capital's bargaining power vis-à-vis labor over the past few decades' (221). In short, one may dispense with the elasticity explanation, and the associated theory of profit rates, and rely entirely upon the role of bargaining power - and the changing institutions and mechanisms governing it, in different eras and places, over the last two centuries ( $c f .305,312,332,510)$. The aggregate production function is not a necessary building block for any of Piketty's findings concerning distributional dynamics. In fact, if $r$ is taken as given - as Piketty, in practice, commonly assumes (at about 5 per cent) throughout the book $^{5}$ - or rising, then it follows by definition that rising $\beta$ will be associated with rising $\alpha$.

\footnotetext{
${ }^{4}$ But in the marginalist theoretical framework to which Piketty evidently subscribes, the return on capital is supposedly a compensation for the disutility of 'waiting' (of not consuming). See also his observations on the supposed marginal productivity of Bill Gates, whose 'contributions depended on the work of thousands of engineers and scientists ... without whom none of his innovations would have been possible' (444-5; cf. 511). There is also a somewhat sceptical discussion of the 'golden rule' of accumulation, as derived from marginal productivity theory $(562-5)$.

${ }^{5}$ See, for example, 53, 121, 131, 162, 202, 229, 233, 361, 366, 431, 453, 572; and: 'In both France and Britain, from the eighteenth century to the twenty-first, the pure return on capital has oscillated around a central value of 4-5 percent a year ... . There has been no pronounced long-term trend. ... It is possible, however, that the pure return on capital has decreased slightly over the very long run .... . [But] we cannot rule out the possibility that the pure return on capital will rise to higher levels over the next few decades' (206).
} 
Piketty's interpretation of the causal structure of the dynamics then appears as follows. The GDP growth rate $(g)$ is an independent variable in equation (3), determined in the conventional supply-side manner, so ultimately driven by the growth of potential productive capacity, in turn reducible to growth of productivity per worker plus population growth (or more strictly, growth of labour supply). His acceptance of that approach to growth is a natural accompaniment to his endorsement of marginal productivity theory (more on this below). Likewise $s$ is treated as an independent variable. These two variables then determine the path of $\beta$, the ratio of $s$ to the initial value of $\beta$ being the growth of wealth. Or, if $g$ and $s$ take stable values, they determine the steady-state $\beta$ - the level to which $\beta$ tends in the long run (equation (3)). The capitalincome ratio is hence an independent variable in equation (2). Inserted into that equation, $\beta$ then determines the path of $r$ and $\alpha$ - or the steady-state value to which $r$ and $\alpha$ tend in the long run - via recourse to marginal productivity theory (equations (17), (18)). The $\sigma>1$ restriction renders this consistent with $\beta$ and $\alpha$ simultaneously rising; although In fact, Piketty's empirical results are that $\alpha$ has decreased over the very long run, 1800-2010, from 35-40 per cent to 25-30 per cent, but on an upward trajectory since the 1970s (222-4).

The normal distributional dynamics of rich versus poor - whether the former are specified as the richest $1 \%, 10 \%, 20 \%$ (or whatever) - then depend upon the configuration of values in inequalities (12) and (15) above: the rich's initial shares in incomes and wealth, relative saving rates of rich and poor, the nonwage-income share and $g / r$. A low value of $g / r$, projected also into the future, is the focus of much attention (350-58, 361-8, 394-401, 410-11). Piketty's empirical results also show a decline in the share of wealth owned by the top decile, until the 1970s, in favour of the wealth share of the next $40 \%$ of the population - the rise of a middle class - with the remaining $50 \%$ still having little (346-50). And there is a revived importance of inherited wealth for distribution, rebounding subsequent to its mid-twentieth-century decline (377-429), with the empirical relevance of the life-cycle theory of saving repudiated in this context (384, 391-2, 399-400, 428). As an instrument for organizing the analysis of inheritance dynamics, Piketty here has recourse to an identity that may be regarded as his third and final fundamental equation (along with equations (2) and (3) above):

$$
b_{y}=\mu m \beta
$$

where $b_{y}$ is the aggregate flow of annual inheritance (and gifts) as a proportion of aggregate national income, $\mu$ is average wealth of individuals at time of death relative to average wealth of living persons and $m$ is the mortality rate (383-5). This enables analysis of the determinants of the dynamics of the aggregate of inheritances over time; further data are required in order to estimate the distribution of the aggregate (407-24).

In fact, notwithstanding that inheritance is a transparently arbitrary element of the distribution of wealth, the contribution of inheritance to the dynamics of distributional inequality is only of decisive normative significance if one supposes that the inequality 
that would occur in the absence of inheritance would be ethically justifiable and/or otherwise expedient. Quite apart from how income-earning wealth is acquired, the rates of remuneration of both the various kinds of labour and the various forms of incomeearning wealth are governed, to a very substantial extent, by conventions resulting from socio-political factors. Those conventions are arbitrary from the standpoint of both justice and expedience. (That is to say, with respect to the latter, they are not necessary or functional for the supply of the relevant production inputs to be forthcoming; they are not required 'supply-prices'.) Even if all wealth ownership results from individuals' own saving - out of labour income and income from wealth only acquired by their own saving, with no inheritance (nor capital gains) - the resulting distribution of wealth can be no more defensible than the income distribution, and associated rates of remuneration, from which it arose.

With respect to the dynamics of $r$ and $\alpha$ - and for that matter, the increasing inequality within the labour income category - these are better understood within the classical theoretical framework, in which the general rate of return on capital is not uniquely determined by narrowly economic parameters (as in marginalist theory) but is subject to wider socio-economic forces, commonly summarized by reference to bargaining power. It is the 'degree of freedom' in the modern reconstruction of the classical approach to competition, profit-maximizing choice of production methods, price determination and its interrelationship with functional distribution, which provides the 'space' for sociopolitical forces to naturally play a fundamental role in these dynamics (Kurz and Salvadori 1995, pp. 94-426). From the marginalist standpoint, these wider forces obvious to close observers of the reality of distribution - appear as a kind of artificial intrusion into the economic process. Relative wages also are in substantial measure governed by social conventions and socio-political forces.

A consideration of these wider forces would point to the following key issues: the general level of real wages over time results from the relationship between the dynamics of money wages versus commodity prices; the ratio of money prices to money wages is governed by the set of rates of return on capital in different employments; this course of money wages relative to prices depends upon the whole set of institutions - including the legal framework, the size and character of the public sector, the extent and forms of labour unionism, tax policy - governing the balance of bargaining power around the labour contract; at the same time, rates of return on the variety of capital investments depend upon central banks' interest rate policies and the spreads between the consequent riskless rates of return and wider yields; those spreads in turn depend upon differential risk and illiquidity, costs of intermediation, restrictions on capital mobility that generate monopoly power and so on; the distribution of rising value-added per worker resulting from technical progress is also determined by the balance of these forces (see, e.g., Stirati 2001; Cesaratto et al. 2003). And all this is shaped by the specific histories and sensibilities of 'place'. There is no intrinsic, determinate and systematic relationship between the accumulation of capital proper (produced means of production), or accumulation of wealth, and rates of return on investments - or between 
capital-output (or wealth-income) ratios and rates of return. (At least this is so, so long as gross rates of return cover minima compensating for risk, illiquidity, managerial costs and so on.) There is no need here to revisit the ways in which these forces, institutions and mechanisms have changed since the 1970s. The return of large-scale unemployment was obviously a crucial factor. Unemployment is an issue hardly mentioned, and only in passing, in Piketty's book.

I asserted above (this section) that in Piketty's distributional dynamics, the GDP growth rate is determined in the conventional supply-side manner. In fact, this is never made very explicit in the book. It is as if this conventional causation is regarded as so obvious (rather like the marginal productivity theory of $r$ ) that it can be more or less tacitly taken for granted (see 42, 69-70 with 586, n. 35, 72-4, 148-9, 460). So it can be unclear, when growth rates are discussed in terms of population and productivity growth, whether the recourse is merely to the identity, that GDP growth (approximately) equals population growth plus productivity growth per capita. This is how growth rates are formulated by Piketty, rather than in terms of employment growth and productivity growth per worker. In any case the same issue arises in either formulation. Is it just a tautological decomposition of growth rates - which is consistent with both supply-side and demand-side explanations of growth - or is the growth of productive capacity causing growth? That GDP growth approximately equals employment growth plus productivity growth per worker is true by definition; that GDP growth approximately equals labour supply growth plus productivity growth per worker entails a supply-side theory. But in his brief interpretation of the 'Cambridge' capital debates, mentioned above, Piketty asserts that 'the growth rate must ... be equal to the growth rate of the population ... and productivity' (230). This clearly enough amounts to affirming that equilibrium or long-run growth is supply-side determined full-employment growth.

This affirmation, in any case, is logical: endorsement of marginal productivity theory entails also endorsement of a supply-side theory of activity levels and growth, at least for the long run, since that theory of distribution is simultaneously a theory in which the demand for factors of production adapts to their supply. Abandoning marginal productivity theory thereby enables room for a more sensible, Keynesian demand-side approach to activity levels including growth dynamics. If growth is demand-determined along Keynesian lines, rising $\alpha$ (in combination with rising $\beta$ ) - a combination that does not require marginal productivity theory for its explanation - can feed back upon the critical $g / r$ ratio by dampening growth, thereby reinforcing adverse distributional dynamics. The plausible supposition that a larger proportion of nonwage income than of wage income is saved means that rising $\alpha$ will tend to dampen consumption demand, with follow-on effects to induced investment demand - although, as was seen in the run-up to the Global Financial Crisis, increasing debt can postpone these consequences of rising inequality, for a time. (Both higher $s$ and lower $g$ increase the steady-state value of $\beta$.) How much all this might affect the empirical orders of magnitude of the relevant aggregate variables is another matter; and Piketty's historical empirical results 
obviously do not depend upon supposing any particular growth theory, although his projections of future growth do, to some extent.

Involuntary unemployment arising from demand deficiency - along with its relevance to distribution via the balance of bargaining power - is also probably directly relevant to the situation of the bottom 50 per cent who have virtually no wealth. Even though, in the developed economies, many if not most of these people have wages above customary subsistence, so that they are capable of some positive saving, they are more subject, and particularly vulnerable, to 'shocks' that wipe out any accumulated wealth like ocean swimmers trying to get out beyond the waves but constantly being thrown back to the shore. Even merely periodic bouts of temporary unemployment can act in this manner. The active pursuit of full employment by policy is important not only for the sake of providing decent work for the involuntarily unemployed themselves, but also, directly and indirectly, for distributional reasons. There is no shortage of public investment that can usefully be undertaken, particularly in the context of contemporary challenges to the maintenance of the natural environment $(519,540-41,565-9)$.

\section{WAGES, PROFITS AND OTHER INCOMES}

In Piketty's conceptual framework wage income (including imputed labour incomes of the self-employed) and nonwage income are mutually exclusive and collectively exhaustive categories; and all assets earning nonwage income are classified as 'capital' (18). But on the one hand, since not all income-earning nonhuman assets are capital proper (produced means of production or financial claims to them), nonwage income includes revenues that are not profits proper, most notably, rents from scarce natural resources. Hence Piketty's $r$ is not even the average ex post rate of profit proper, let alone the normal required rate of return on capital (nor $\alpha$ the profit share proper). On the other hand, since the wage-income category includes all revenues that are not attributable to nonhuman assets, it includes the salaries, and super-salaries, of the managerial class and others (including financial management of course). And then there is the murky question of how and where remuneration of 'entrepreneurship' fits into all this.

Most obviously, incomes from scarce natural resources pertain to rents from unimproved land and other natural resource stocks. To the extent that this is about agriculture, it is of no great moment to Piketty's aggregate empirical results since nonwage agricultural incomes are such a small proportion of aggregate nonwage incomes, at least in the developed world. (The 'capital' value of agricultural land net of improvements will be its rental income capitalized at an appropriate rate of return.) But to the extent that it is also about other natural resource stocks (e.g., minerals, oil, gas), and the scarcity value of prime residential land, it might be rather more significant. The revenue and capitalized value of the former can change dramatically, as a result of 
technical change that renders previously 'useless' resources economically exploitable; ${ }^{6}$ rising scarcity rents from the latter will also be capitalized into the value of prime residential property ( $c f .222-7$, esp. n. 30).

The 'labour' incomes of at least some of the super-salaried might also be explained (and rationalized) as returns on scarce natural human resources. This might well apply, for example, to star sportspersons whose natural talents are rare, relative to the revenues generated in mass-audience sports. But there is a difference between explaining and rationalizing: if, in fact, these stars would participate in those sports, in the same manner, for substantially lower incomes, then their higher earnings are not the supplyprice of their activity, but rather, a (taxable) scarcity rent. ${ }^{7}$ With regard to managerial super-salaries, which are the dominant element in extreme 'wage' incomes, Piketty outlines results from some earlier research which shows that the elasticity of executive super-salaries is greater with respect to 'luck' than with respect to 'talent' (512; Piketty et al. 2014). And should incomes from intellectual property (notably, patents and copyright) be conceived of as returns on capital (including human capital) or monopoly rents on 'non-reproducible' assets, where the non-reproducibility results merely from a legal restriction? It is highly implausible to think of a normal rate of return on capital which acts as the supply-price to bring forth an 'optimal' quantity of intellectual capital. Success in invention and innovation also has a significant lottery element.

The managerial super-salaries cannot plausibly be rationalized as competitive supplyprices of forms of extraordinarily productive labour. It is no more plausible to regard these remunerations as rents for particularly remarkable scarce natural human resources that add extraordinary value to enterprises. More generally, even the remuneration of entrepreneurship - understood in the strict and substantial sense of innovation - cannot sensibly be regarded as a supply-price of that innovation, a necessary ex ante return for it to be forthcoming. Piketty uses the term entrepreneurship rather loosely, sometimes to refer to innovation but also to refer merely to management functions $(41,53,204-05$, $280,439-47,571-2)$. It is of course reasonable to suppose that risk-bearing - associated with well-defined probability distributions over all possible outcomes of various economic activities - has a calculable supply-price. (In the case of capital exposed to risk, this will be in terms of a premium in the rate of return, over and above the riskless rate of interest.) But innovation belongs to the realm of unmeasurable uncertainty; it is about unprecedented economic activity in one sense or another.

What the key seminal contributions to the systematic economic analysis of entrepreneurship point to is that the notion of an ex ante required rate of remuneration

\footnotetext{
${ }^{6}$ And environmental unsustainability - notably, associated with climate change - may result in 'stranded assets' which suffer windfall losses in value (even if those losses should have been foreseen), due to their embodying unsustainable, obsolete technologies.

${ }^{7}$ As against sportspersons, the incomes of entertainment 'celebrities' are more akin to luck - rather like winning a lottery - since there are more than a few aspirants, who do not 'make it', but who would be more or less perfect substitutes for most of those who do. Whether or not natural, the talents involved are not so scarce. In any case, celebrity incomes are only a very small fraction of the aggregate of extreme salary incomes (302-03).
} 
for entrepreneurship in the substantial sense, as innovation - remuneration that would be akin to normal supply-prices for non-innovative labour or capital - does not really make sense (Schumpeter 1934 [1911]; Knight 1921; Aspromourgos 2014, pp. 22-5, 348). Rather, the entrepreneur, properly understood in this substantial sense, is the 'residual claimant' to the net revenues of an innovative or unprecedented enterprise. And more often than not, the residual will be non-positive; that is to say, the majority of entrepreneurs (properly understood) actually fail. The hope of extraordinary profit, in some indeterminate sense as to magnitude, might be a motivation (or even the sole motivation) to entrepreneurial activity; but there can be no definite required rate of return to entrepreneurship, necessary to bring it forth - whether it is conceived of as a kind of labour provision or as capital provision. It is common for inequality to be defended against its detractors by arguing that it is the necessary price of innovation. Even if there were a trade-off between reduced economic inequality and innovation, this would thereby require a judgement of relative social benefit. ${ }^{8}$ It would be most uneconomist-like simply to presume that innovation is worth any price, in terms of equality foregone.

It may be added that the Keynesian demand-side approach to activity levels and growth, as against the conventional supply-side approach, also has an implication for the theory of profits, supporting and reinforcing other grounds for rejecting the conventional approach to profits. Instead of aggregate commodity demand adapting to aggregate potential supply (ultimately regulated by the quantity and productivity of factors of production supplied), and hence the level of investment adapting to the quantity of saving, aggregate commodity supply adapts to aggregate demand, the residual observable underutilized resource being unemployed labour. This process whereby aggregate commodity supply adapts to aggregate demand is one and the same process as saving adapting to investment. Thereby, the notion of the rate of return on capital as the necessary supply-price to bring forth the saving to 'finance' investment is also fundamentally undermined (but subject to the lower bound of the afore-mentioned minima covering risk and so on). There is no unique, 'equilibrium' general rate of return on capital (or rate of interest) required for the functioning of the economic system. This line of reasoning is fundamental to the thinking behind John Maynard Keynes's 'euthanasia of the rentier' (Aspromourgos 2011).

\footnotetext{
8 Whether innovation can be supposed automatically to translate into widely distributed growth in per capita consumption is a question as well, which we leave aside. One may add that low or zero taxation of inheritances is certainly not necessary as an inducement to any economic activity. Those conservatives or economic liberals who decry government transfer payments and other outlays supporting the poor, on the basis that they supposedly stifle individual self-reliance and initiative, might consider turning their attention to inheritance.
} 


\section{CONCLUSION: POLICY AND POLITICS}

Commentary on the policy dimension of Piketty's book rather naturally has focussed on his striking advocacy of a progressive global tax on 'capital' (515-39, 555-6, 573). It therefore may be emphasized that he is a long way from being a single-tax zealot:

discussions of a tax on capital often push people into extreme positions (so that they either reject the idea out of hand or embrace it as the one and only tax, destined to replace all others).... In my view, it is urgent to lower the temperature of the debate and give each argument and each type of tax its due. A capital tax is useful, but it cannot replace all other taxes.' $(642, \text { n. } 17)^{9}$

appropriate updating of the last century's social-democratic and fiscal-liberal program is essential ... two fundamental institutions ... must continue to play a central role in the future: the social state and the progressive income tax. (515)

Further in relation to his policy views, Piketty doubts that inflation is a reliable policy for reducing inequality $(106-09,209-12,452-5,544-7)$ and is similarly rather averse to public debt (129-35, 540-70). Governments should tax the rich rather than sell them bonds $(540,566)$.

It is also made clear that revenue-raising is not the key purpose of the capital tax rather, combined with global 'democratic and financial transparency', the objective is 'to regulate capitalism' (effectively) - although the estimated revenue is not insignificant $(518,527-30)$. And just as Piketty's capital is not capital proper, so his capital tax in fact is a net worth tax. Hence conceptually, it would apply, above some threshold of total net worth, also to residential housing - the big component of Piketty's capital, alongside capital proper - but net of mortgage debt. To that extent, it is arguably more equitable than current common forms of taxation of residential housing and land, based on gross value (517). One may add that for a low-growth world, it is difficult to escape the conclusion that policy to directly reduce the after-tax rate of return on capital is imperative. Keynes's euthanasia of the rentier via a low or zero riskless real rate of interest, as a permanent policy, should be taken seriously. Also from a Keynesian standpoint, there is no reason to expect redistribution to compromise economic growth, and indeed, there is no compelling empirical evidence that redistributive policies are associated with lower growth (e.g., Ostry et al. 2014).

The minimum progressivity of a net worth tax would be a threshold combined with a uniform single tax rate. One tentative suggestion by Piketty is a $€ 1$ million threshold plus a two-step rate structure; 1 per cent from $€ 1$ million to $€ 5$ million and 2 per cent above that (517). Of course, notwithstanding the existence of technical and other practical difficulties in the way of such a net worth tax, the great obstacle is political,

\footnotetext{
${ }^{9}$ While this quotation is from the endnotes, the text proper also makes his position along these lines very clear $(471,473,512-14,518,524-7)$.
} 
not the least element of which is the need for global coordination. Global capitalism with more or less unrestricted international financial flows (as well as other forms of international economic mobility beyond merely trade flows) functions, at a global level, in a manner analogous to that which one strand of liberal political thought hopes for from federal political systems, at a national level: generating fiscal and regulatory competition between States and thereby minimizing the policy reach of government ( $c f$. $221,464,496-7,560-62)$. In the absence of fairly comprehensive international implementation, sanctions would have to be imposed upon non-complying jurisdictions. Piketty knows that the proposal is rather 'utopian' (his term; 27, 471, 515). But the temptation to therefore dismiss it should be resisted. That which is utopian policy today, may not be so in the future; and more importantly, it will certainly remain utopian if it is never seriously entertained. Universal adult suffrage was utopian once too, as well as many other current egalitarian norms (notably, universal health care and school education). I am reminded of a quotation from Francis Bacon (1875 [1620], p. 48), used as an epigraph in Aspromourgos (2011), as an expression of Enlightenment optimism: 'It would be an unsound fancy and self-contradictory to expect that things which have never yet been done can be done except by means which have never yet been tried.' All human progress begins from contemplation of the unprecedented.

The failure of the contemporary political class, in terms of both ethics and competence, stands out here as the real basis for pessimism. As mentioned earlier, although Piketty's capital is not capital proper, from the standpoint of economic and political power this measure of marketable non-human assets captures the command the wealthy have over resources. However much labour productivity growth might enable average real wages to rise, the one thing an average wage-earner will never have the power to purchase is another average wage-earner ( $c f .257$ ), in contrast to the rich - and the very rich can afford to purchase politicians and other relatively high income-earners as well ( $c f$. 335). If Piketty is right in his judgement, expressed at one point, that extreme inequality in the twenty-first century could lead to political conflict of crisis proportions, then the absence of a sufficiently progressive tax regime might threaten the viability of the liberal polity and economy $(439 ; c f .497,539)$. As he also points out, any existing broad consensus of support for the social state (social democracy) and the tax levels that facilitate it must be undermined by little tax being paid at the highest levels of income and wealth - particularly the support of the (well-taxed) middle classes (4967). The resilience of liberal capitalism, with or without a social-democratic element, should not be taken for granted - as against its capacity for self-destruction, including its morphing into illiberal capitalism. Piketty at one point quotes Josiah Wedgwood, with tacit approval: 'political democracies that do not democratize their economic systems are inherently unstable' (508; $c f .569-70)$. 


\section{REFERENCES}

Aspromourgos, T. (2011) 'Can (and Should) Monetary Policy Pursue a Zero Real Interest Rate, Permanently?', Metroeconomica, vol. 62, pp. 635-55.

Aspromourgos, T. (2014) 'Entrepreneurship, Risk and Income Distribution in Adam Smith', European Journal of the History of Economic Thought, vol. 21, pp. 21-40.

Bacon, F. (1620) Novum Organum; as transl. (The New Organon) in J. Spedding, R.L. Ellis and D.D. Heath (eds) (1875) The Works of Francis Bacon ... , vol. 4 (Translations of the Philosophical Works, vol. 1), Longmans et al., London.

Cesaratto, S., Serrano, F. and A. Stirati (2003) 'Technical Change, Effective Demand and Employment', Review of Political Economy, vol. 15, pp. 33-52.

Knight, F.H. (1921) Risk, Uncertainty and Profit, Boston, MA: Houghton Mifflin.

Kurz, H.D. and N. Salvadori (1995) Theory of Production: a Long-Period Analysis. Cambridge: Cambridge University Press.

Ostry, J.D., Berg, A. and C.G. Tsangarides (2014) 'Redistribution, Inequality and Growth', IMF Staff Discussion Note, no. SDN/14/02.

Piketty, T. (2014) Capital in the Twenty-First Century, Cambridge, MA: Belknap Press.

Piketty, T., Saez, E. and S. Stantcheva (2014) 'Optimal Taxation of Top Labor Incomes: a Tale of Three Elasticities', American Economic Journal: Economic Policy, vol. 6, pp. 230-71.

Ricardo, D. (1817) On the Principles of Political Economy, and Taxation, London: John Murray; in P. Sraffa (ed.) (1951) The Works and Correspondence of David Ricardo, vol. 1, Cambridge: Cambridge University Press.

Schumpeter, J.A. (1934) The Theory of Economic Development: an Inquiry into Profits, Capital, Credit, Interest, and the Business Cycle, Cambridge, MA: Harvard University Press (transl. R. Opie, from the 2nd German edn 1926; 1st German edn 1911).

Smith, A. (1776) An Inquiry into the Nature and Causes of the Wealth of Nations, 2 vols., London: Strahan and Cadell; in R.H. Campbell, A.S. Skinner and W.B. Todd (eds) (1976) The Glasgow Edition of the Works and Correspondence of Adam Smith, vol. 1, Oxford: Clarendon.

Sraffa, P. (1960) Production of Commodities by Means of Commodities: Prelude to a Critique of Economic Theory. Cambridge: Cambridge University Press.

Stirati, A. (2001) 'Inflation, Unemployment and Hysteresis: an Alternative View', Review of Political Economy, vol. 13, pp. 427-51. 
Tony Aspromourgos

School of Economics

University of Sydney

Sydney NSW 2006

Australia

Email: tony.aspromourgos@sydney.edu.au 